\title{
Effect of distributed generation plants' automatic controllers on power quality factors
}

\author{
Bulatov Yu.N. 1, ${ }^{*}$, Kryukov A.V., ${ }^{2,}$, Nguyen Van Huan ${ }^{3}$ \\ ${ }^{1}$ Bratsk State University, Bratsk, Russia \\ ${ }^{2}$ Irkutsk State Transport University, Irkutsk, Russia \\ ${ }^{3}$ Irkutsk National Research Technical University, Irkutsk, Russia
}

\begin{abstract}
Currently, energy generation industry transition to a new technological platform based on smart electrical energy systems (EES) is underway, with EES equipped with active-adaptive mains. This platform involves a large-scale use of digital devices and significant electrical energy (EE) generation using distributed generation (DG) plants which are to be created by power consumers. These plants can operate as parts of existing grids, or be pooled in network clusters. To implement smart EES, the development of new approaches is required for production, distribution and EE consumption modes management. The article is dedicated to the issues of DG plants application to raise efficiency of non-traction consumers power supply systems. In this case, a special attention was paid to enhancing the electrical energy quality via application of the DG plant which is controlled by concordantly set generator automatic voltage regulator (AVR) and automatic speed governor (ASG). For optimization and harmonization of AVR and ASG settings a method of nonparametric identification of the 'turbine-generator' system was used which can be represented as complex activation functions of main channels and crosslinks of regulators and the generator. The study was carried out in Matlab environment on a created railroad power supply system model. The studies conducted helped to detect that application of DG plants with concordantly set AVR and ASG makes it possible to enhance power quality for non-traction consumers and ensure dynamic stability and resilience of railroad line power supply system.
\end{abstract}

\section{Introduction}

Requirements for enhancing efficiency, resilience and reliability of power supply to consumers are applied to contemporary electrical energy systems (EES). These increasingly toughening requirements are supposed to be met in conditions of power competitive market via introduction of Smart Grid [1-9] technologies allowing to more effectively use energy resources. Smart Grid technologies involve a broader application of distributed generation (DG) plants, which implies a set of power installations operating in close proximity to consumers. To implement smart EES, the development of new approaches is required for production, distribution and electrical energy (EE) consumption modes management.

The use of distributed generation allows to enhance power supply efficiency and reliability and to reduce power supply costs. In addition, the studies conducted [10] indicated that power quality factors can be enhanced substantially using DG plants. This result is the most demanded in power supply systems (PSS) of railroads non-traction consumers $[11,12]$. Power quality factors $(\mathrm{PQF})$ can exceed the permissible limits in such PSS.

bulatovyura@yandex.ru
Below is the analysis of the issues of distributed generation plants application to raise efficiency of nontraction consumers power supply systems. In this case, a special attention was paid to enhancing the quality power supplied to non-traction consumers via application of the DG plant which is controlled by concordantly set generator automatic voltage regulator (AVR) and automatic speed governor (ASG). The study was carried out in Matlab environment on a created railroad power supply system model.

\section{Method for harmonizing DG plant regulators settings}

Algorithm of the method for harmonization of AVR and ASG settings includes identification of DG plant's the 'turbine-generator' controlled system, regulators setting and stability reserve assessment. Algorithm of regulators concordant setting is based on standard coefficients method which is an approximation of characteristic polynomials factors of the system under study by simultaneous changes in AVR and ASG coefficients of tuning to the standard (desired) forms, a priori possessing the required quality indicators for transient process and the necessary stability margin. It is 
suggested that Butterworth polynomials should be used as desired polynomials. The choice of these polynomials is justified by the following factors: Butterworth filter has only poles (all zeros of transfer function are located on infinity) which significantly simplifies the task of finding the desired characteristic equation; the filter is stable for any order and possesses a smooth transition curve.

Optimal AVR and ASG tuning coefficients are determined subject to solution of optimization problem using the genetic algorithm reducing the following quadratic criterion to minimum [13]:

$$
J=\int_{0}^{\Omega} e^{2}(j \omega) d \omega \rightarrow \min ,
$$

where $e(j \omega)=D^{D}(j \omega)-D^{M}(j \omega)-$ error between the desired polynomial coefficients $D^{D}(j \omega)$ and model polynomial $D^{M}(j \omega)$, containing the required coefficients of controllers settings.

For identification purposes the DG plant 'turbinegenerator' system was represented as complex activation functions of the main channels and regulators cross couplings and generator (fig.1). The identification method is oriented to passive approach while using apparatus of discrete Fourier transform and wavelet transform technology to select regulators noise used as test effect on the system [14].

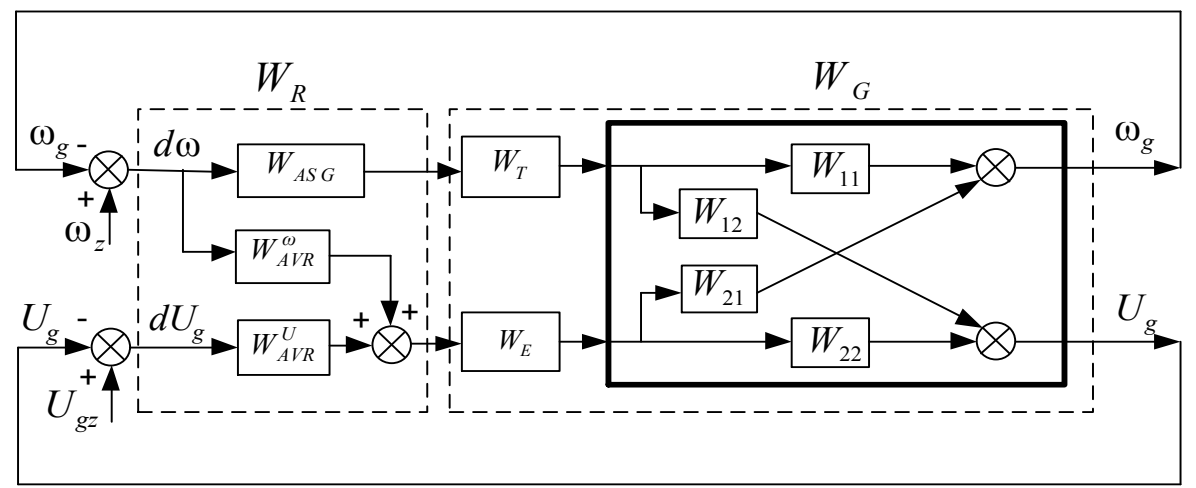

Fig. 1. Structural representation of the 'turbine-generator' controlled system.

Algorithms of regulators concordant setting and identification of DG plant the 'turbine-generator' identification system are implemented in the specialized software application whose description is given in [15].

\section{Description of the model and the study results}

The studies were conducted for railroad power supply system (RPSS) provided in fig. 2. A power supply region

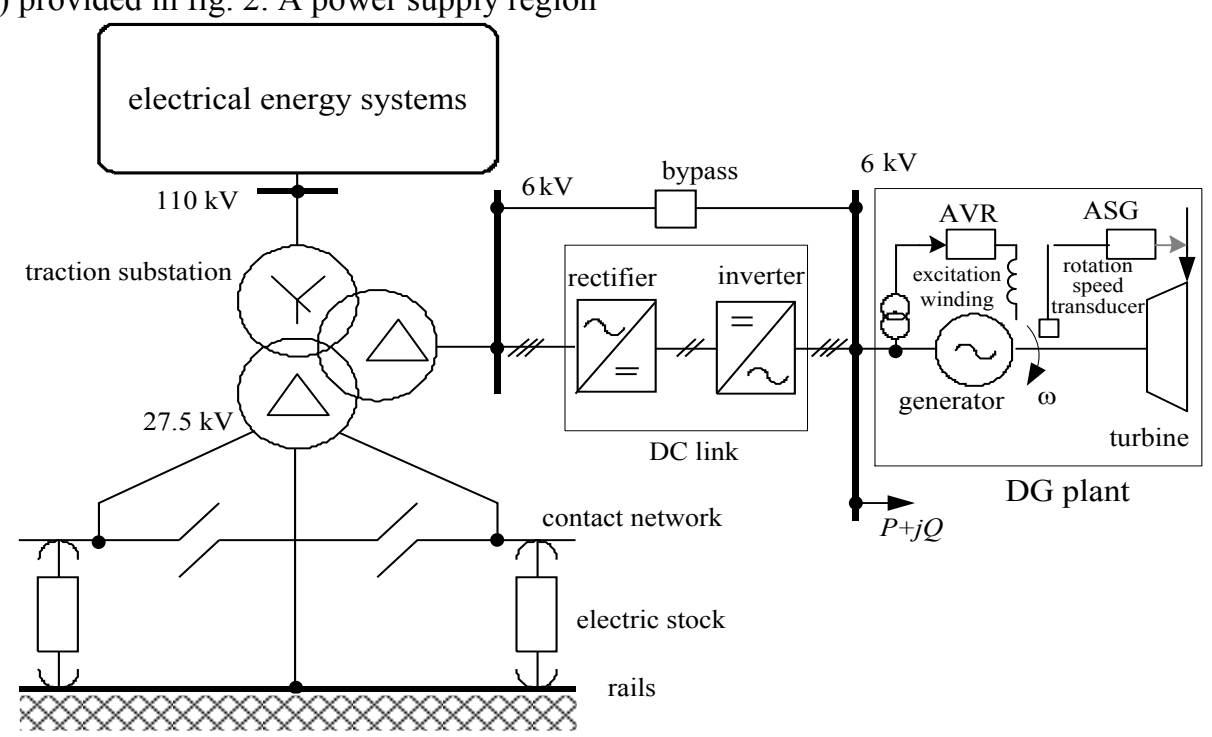

Fig. 2. A fragment of RPSS.

with DG plant supplying a load group with total power of 5.5 MVA was simulated as connected to traction substation via DC link. DG plant power was equal to 2.5 MVA.

Fig. 3 provides a diagram of the model implemented using Simulink and SimPowerSystems software packages of MATLAB system. 


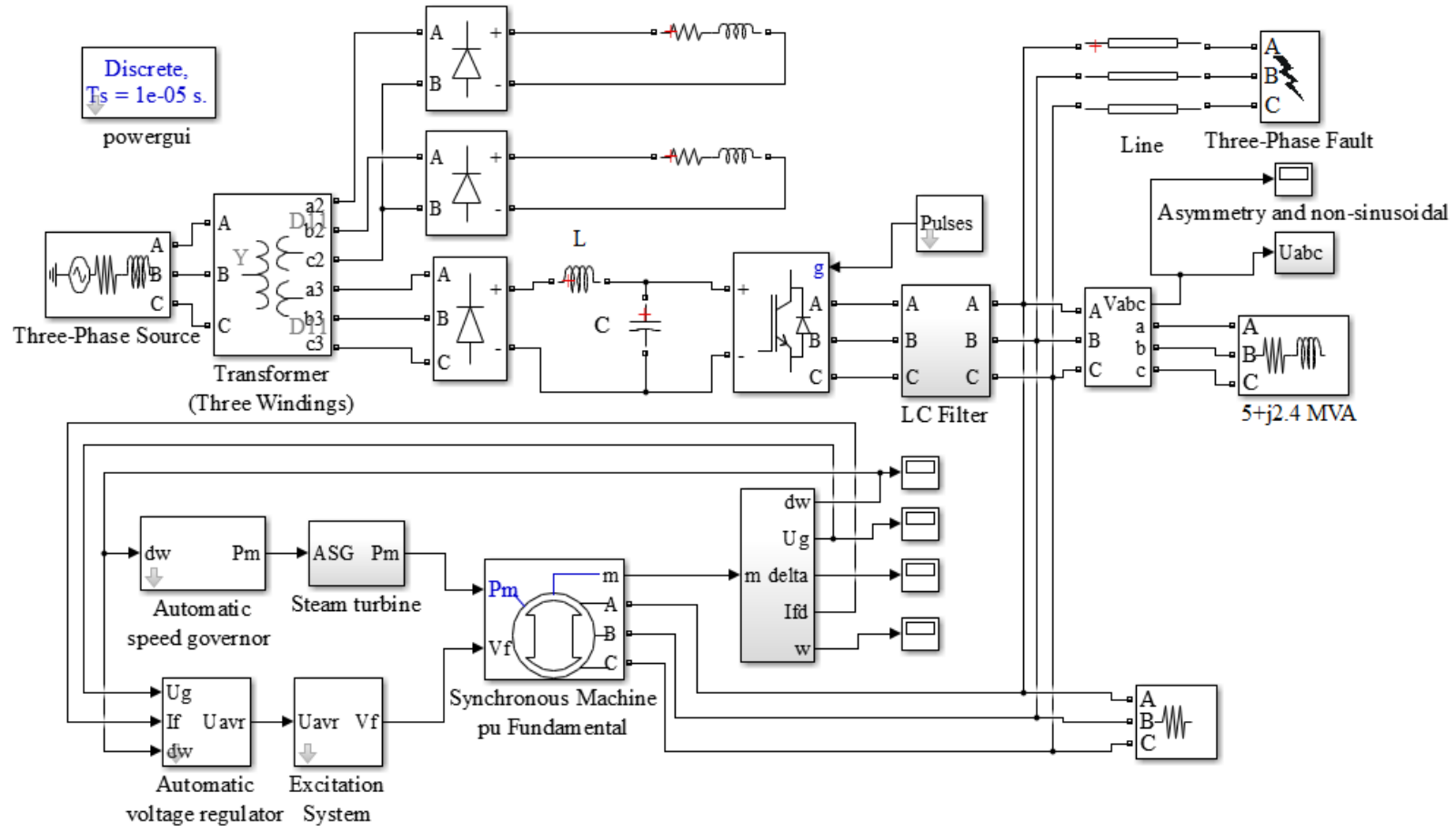

Fig. 3. Diagram of power generation system model under study.

DG plant generator (Synchronous Machine pu Fundamental unit in fig. 3) is modeled by high-voltage synchronous machine actuated by a steam turbine, whose mathematical model (net of intermediate steam overheating) can be represented by the following activation function:

$$
W(s)=\frac{P_{m}}{\mu}=\frac{1}{T_{m} s+1},
$$

where $P_{m}$ - turbine power; $\mu$ - opening of the control valve; $T_{m}$ - turbine time constant, determined by delay in steam energy conversion into mechanical energy (averagely $T_{m}$ equals to $0.2 \mathrm{~s}$ ); $s$ - Laplasian operator.

Excitation thyristor system model (Excitation System unit in fig. 3) was created based on equations describing thyristor converter and input amplifier [16]. Input amplifier is simulated by first-order aperiodic link with amplification coefficient $k_{a}=1$ and time constant $T_{a}=0.001 \mathrm{~s}$. Thyristor exciter is simulated by first-order aperiodic link with coefficient $k_{e}=1$ and time constant $T_{e}=0.025 \mathrm{~s}$.

To control frequency and voltage in different operating modes, the DG plant was controlled by ASG (Automatic speed governor unit in fig.3), which is basically a proportional-integral-differential (PID) regulator, and microprocessor AVR (Automatic voltage regulator unit).

For purposes of studying AVR and ASG influence and the influence of their settings on PQF, modeling of turbogenerator operation in railroads power supply system was carried out (fig. 3). The modeling results are presented in table 1 and are shown in fig. 4 and 5 .

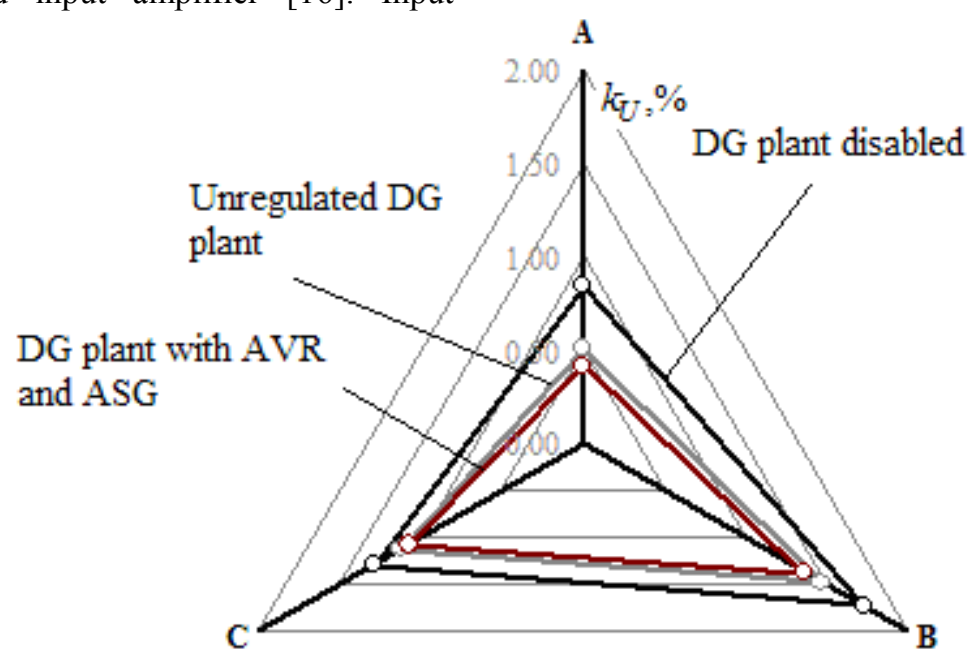

Fig. 4. Total coefficients of harmonic distortions. 
Table 1. Power quality factors for unsymmetry and harmonic distortions.

\begin{tabular}{|c|l|c|c|c|c|}
\hline No. & Railroad power supply system operating mode. & $k_{U A B}$ & $k_{U B C}$ & $k_{U C A}$ & $k_{2 U}$ \\
\hline 1 & DG plant is shut down & 0.84 & 1.73 & 1.29 & 0.71 \\
\hline 2 & DG plant is turned on, AVR and ASG - turned off & 0.51 & 1.47 & 1.11 & 0.53 \\
\hline 3 & $\begin{array}{l}\text { DG plant is turned on, concordantly set AVR and } \\
\text { ASG are operating }\end{array}$ & 0.42 & 1.36 & 1.07 & 0.52 \\
\hline 4 & Difference between lines 1 and 3\% & 100.00 & 27.21 & 20.56 & 36.54 \\
\hline 5 & Difference between lines 2 and 3\% & 21.43 & 8.09 & 3.74 & 1.92 \\
\hline
\end{tabular}

Note: $k_{U}$ - total coefficients harmonic distortions; $k_{2 U}$ - negative sequence unsymmetry coefficients

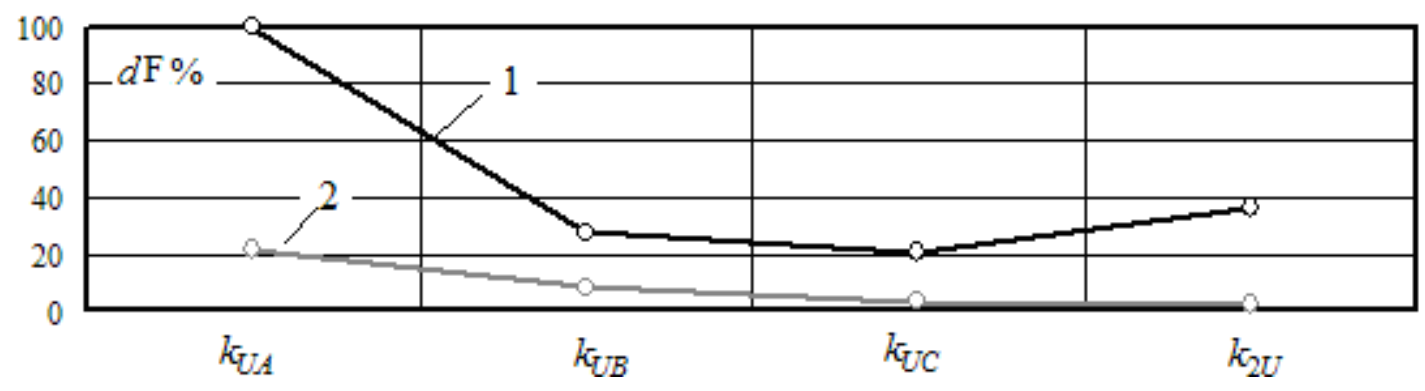

Fig. 5. PQF in different modes of DG plant operation: 1 - difference between lines 1 and 3 tables 1, \%; 2 - difference between lines 2 and 3 tables $1, \%$

Thus, based on modeling of the system provided in fig. 2 we can state that PQF distortions (not going beyond regulatory limits) are, chiefly, created by DC link inverter; in this case, generator, operating for the mains with nonsymmetrical and nonsinusoidal source, starts generating harmonics to the mains and create voltage unbalance. The use of concordantly set AVR and ASG allows to enhance power quality.

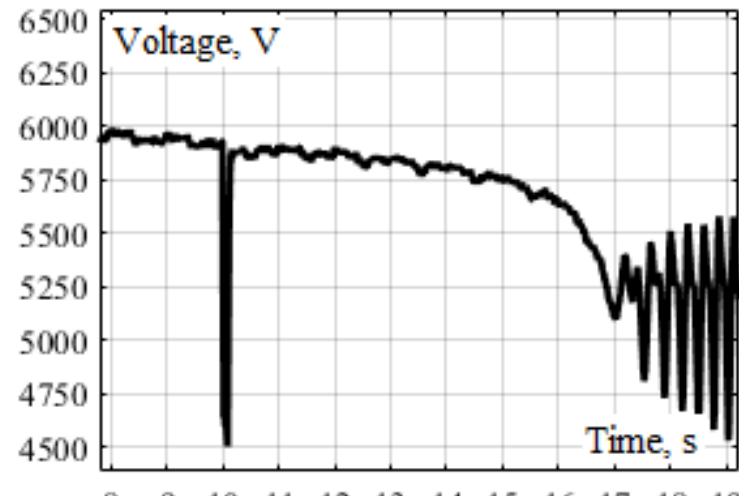

$\begin{array}{llllllllllll}8 & 9 & 10 & 11 & 12 & 13 & 14 & 15 & 16 & 17 & 18 & 19\end{array}$

a)

Fig. 6. Generator voltage change under SC: a) without the use of regulators; b) with the use of concordantly set AVR and ASG

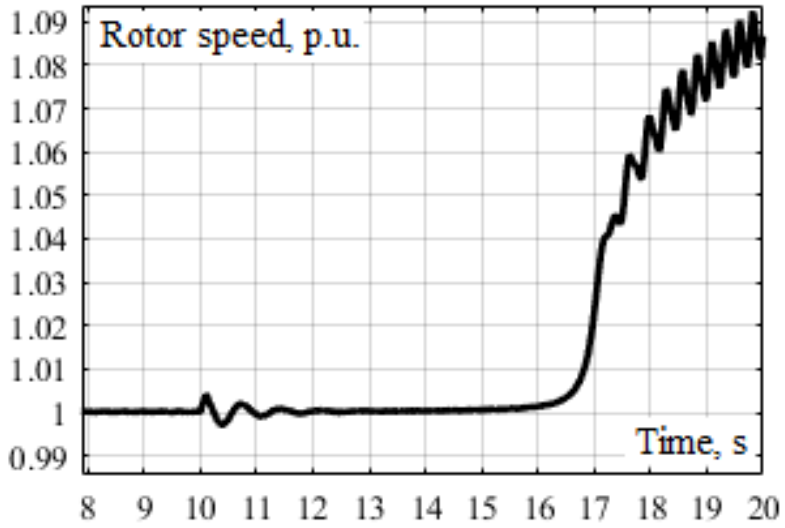

a)

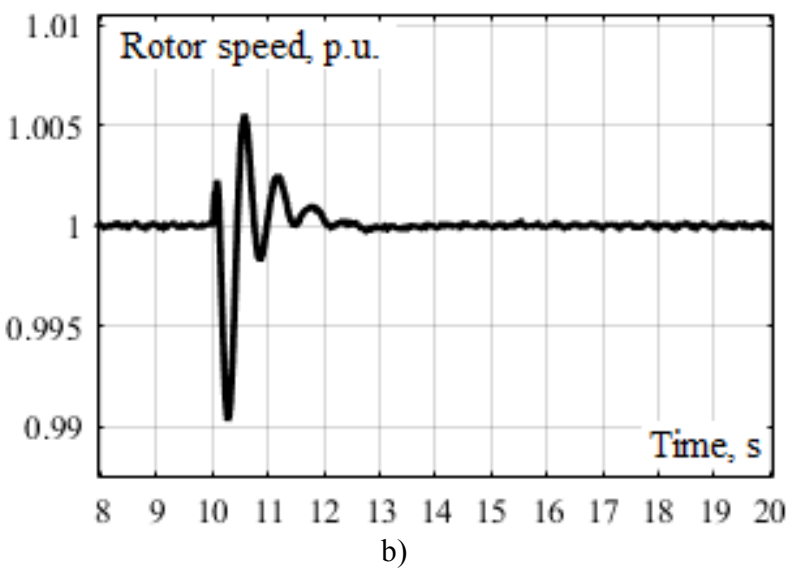

b)

Fig. 7. Generator rotor speed change under SC: a) without the use of regulators; b) with the use of concordantly set AVR and ASG 
Thus, we can note that positive effects of DG plant's AVR and ASG concordantly setting are especially demonstrably manifested in transient states, since the regulators allow to stabilize mains voltage and frequency which influences PQF.

\section{Conclusion}

1. The procedure for distributed generation plant's regulators concordant setting has been proposed that allows to enhance power quality.

2. Modeling results indicated positive influence of concordantly set AVR and ASG on stability margin, tuning and overshoot time for rotor rotation frequency and generator voltage, and on power quality factors in power supply systems of AC railroads non-traction consumers.

3. The effect of DG plant generator's concordant control of AVR and ASG is vividly manifested in transient stages when the regulators allow to efficiently stabilize mains voltage and frequency, which influences power quality factors

\section{References}

1. J. Wang, A.Q. Huang, W. Sung, Y. Liu, B.J. Baliga, Smart Grid Technologies, IEEE Industrial Electronics Magazine, vol. 3. No 2, pp. 16-23 (2009)

2. F.N. Mohsen, M.S. Amin, H. Hashim, Application of smart power grid in developing countries, IEEE 7th International Power Engineering and Optimization Conference (PEOCO) (2013). DOI: 10.1109/PEOCO.2013.6564586

3. B.M. Buchholz, Z.A. Styczynski, Smart Grids Fundamentals and Technologies in Electricity Networks, Berlin Heidelberg: Springer-Verlag, 396 p. (2014)

4. A.V. Kryukov, S.K. Kargapol'cev, Yu.N. Bulatov, O.N. Skrypnik, B.F. Kuznetsov, Intelligent control of the regulators adjustment of the distributed generation installation, Far East Journal of Electronics and Communications. Vol. 17. No. 5. p. 1127-1140 (2017)

5. D. Olivares et al., Trends in Microgrid Control, Smart Grid, IEEE Transactions on , vol. 5, no. 4, pp. 1905-1919 (2014)
6. Yu.N. Bulatov, A.V. Kryukov, K.V. Suslov, Multiagent technologies for control of distributed generation plants in the isolated power systems, Far East Journal of Electronics and Communications. Vol. 17. No. 5. pp. 1197-1212 (2017)

7. F. Katiraei, M. R. Iravani, and P Lehn, Micro-grid autonomous operation during and subsequent to islanding process, Power Delivery, IEEE Transactions on, vol. 20, no. 1, pp. 248-257 (2005).

8. Yu.N. Bulatov, Intelligent control systems for distributed generation plants. Proceedings of Irkutsk State Technical University. vol. 21, no.10, pp. 78-94 (2017). DOI: 10.21285/1814-3520-2017-10-78-94

9. R. Wang, P. Wang, G. Xiao, Intelligent Microgrid Management and EV Control Under Uncertainties in Smart Grid, Springer, 218 p. (2018)

10. Yu.N. Bulatov, A.V. Kryukov, Network clusters in railway power supply systems, Irkutsk: Irkutsk State Transport University, 205 p. (2015)

11. A. Steimel, Electric traction motive power and energy supply. Basics and practical experience, Munchen: Oldenbourg Industrieverlag, 334 p. (2008)

12. Energieversorgung elektrischer bannen / $\mathrm{H}$. Biesenack, E. Braun, G. George, etc. / Wiesbaden: B.G. Teubner Verlag, 732 p. (2006)

13. Yu.N. Bulatov, A.V. Kryukov, Optimization of automatic regulator settings of the distributed generation plants on the basis of genetic algorithm, 2nd International Conference on Industrial Engineering, Applications and Manufacturing (ICIEAM). IEEE Conference Publications, pp. 1-6 (2016). DOI: 10.1109/ICIEAM.2016.7911456

14. Yu.N. Bulatov, A.V. Kryukov, Application of wavelet transform and genetic algorithms to tune automatic regulators of distributed generation plants, Scientific Bulletin of NSTU, Vol.63, No. 2, pp. 7-22 (2016)

15. Yu.N. Bulatov, I.V. Ignatiev, The software package for identification of electric power systems and optimization of stabilization factors of the automatic excitation regulators, Systems. Methods. Technologies, No. 4(8). pp. 106-113 (2010)

16. P.M. Anderson, A.A. Fouad, Power System Control and Stability. Second Edition. IEEE Press, 688 p. (2003) 